DOI: http://dx.doi.org/10.22483/2177-5796.2018v20n2p471-484

\title{
Conselhos de Educação no âmbito do Plano de Ações Articuladas (PAR) em municípios de Mato Grosso do Sul
}

\author{
Regina Tereza Cestari de Oliveira \\ Carmen Lígia Caldas Haiduck
}

Resumo: Este artigo tem como objetivo apreender o processo de criação de Conselhos Municipais de Educação no decurso de dois ciclos (2007-2010; 2011-2014) do Plano de Ações Articuladas (PAR), no contexto da política educacional desses períodos, com destaque para os municípios do estado de Mato Grosso do Sul. Para tanto, a análise baseia-se em fontes documentais. Os resultados indicam que a política indutora do PAR impulsionou a criação desses Conselhos. Estes, por sua vez, poderão contribuir para a gestão democrática da educação em âmbito local.

Palavras-chave: Conselho Municipal de Educação. Plano de Ações Articuladas. Gestão democrática da educação.

\section{Education Councils under the Articulated Actions Plan (PAR) in Mato Grosso do Sul cities}

\begin{abstract}
This paper aims to know the process of creating Municipal Councils of Education during the two cycles (2007-2010, 2011-2014) of the Articulated Actions Plan (PAR), in the context of the education policy of these phases, with emphasis on cities of the state of Mato Grosso do Sul. For this, the analysis is based on documentary sources. The results indicate that the policy of the PAR led to the creation of these Councils. These, in turn, could contribute to the democratic management of education at the local level.
\end{abstract}

Keywords: Municipal Education Council. Plan of Articulated Actions. Democratic management of education. 
OLIVEIRA, Regina Tereza Cestari de; HAIDUCK, Carmen Lígia Caldas. Conselhos de Educação no âmbito do Plano de Ações Articuladas (PAR) em municípios de Mato Grosso do Sul.

\section{Introdução}

Este artigo $^{1}$ tem como objetivo apreender o processo de criação de Conselhos de Educação em municípios sul-mato-grossenses, no decurso do primeiro ciclo do Plano de Ações Articuladas (PAR) 2007-2010 e do segundo ciclo do PAR 2011-2014.

Para tanto, com base em fontes documentais, caracteriza-se, na primeira seção, o PAR no contexto da política educacional brasileira, em que foi definido como instrumento de planejamento estratégico, no âmbito do Plano de Desenvolvimento da Educação (PDE). Na segunda seção destaca-se o Conselho Municipal de Educação, presente no PAR como um dos Indicadores da Área "Gestão Democrática: articulação e desenvolvimento do Sistema de Ensino" a ser considerado pelos municípios, nessa modalidade de planejamento educacional, conforme o documento norteador (BRASIL, 2008, p. 18) e discute-se o movimento de criação desses Conselhos nos estados brasileiros, de modo especifico no estado de Mato Grosso do Sul.

\section{O plano de ações articuladas na agenda do governo Lula da Silva (2007-2010)}

O Plano de Metas Compromisso Todos pela Educação foi instituído pelo decreto n. 6.094, de 24 de abril de 2007, no segundo mandato do governo Luiz Inácio Lula da Silva (2007-2010). Trata-se do dispositivo legal que põe em vigência o Plano de Desenvolvimento da Educação (PDE) (SAVIANI, 2009).

Ressalta-se que o PDE integra a agenda prioritária definida no Plano Plurianual (PPA) ${ }^{2}$ 2008-2011, elaborado nesse governo, com o título "Desenvolvimento com inclusão social e educação de qualidade". A mensagem presidencial enfatiza que o governo pretende, em articulação com os entes federativos e a sociedade, “[...] construir o Brasil, ampliando e reformando a nossa infraestrutura, melhorando significativamente a qualidade da educação, consolidando assim o desenvolvimento sustentável com inclusão social” (BRASIL, 2007a).

\footnotetext{
${ }^{1}$ Os dados resultam do Projeto "Planejamento da Educação em Municípios Sul-Mato-Grossenses: implicações para a gestão democrática e o direito à educação", com o apoio da Fundação de Apoio ao Desenvolvimento do Ensino, Ciência e Tecnologia do Estado de Mato Grosso do Sul (FUNDECT/MS).

${ }^{2}$ A Constituição Federal de 1988 (BRASIL, 1988) define, entre outros, o Plano Plurianual (PPA), como instrumento de planejamento governamental a ser enviado pelo presidente da República ao Congresso Nacional. Esse plano, previsto no Art. 165, deve organizar e viabilizar a ação pública, apresentando os objetivos, as diretrizes e as metas da administração pública federal para um período de quatro anos, sendo que os demais planos e programas nacionais, regionais e setoriais devem ser elaborados em consonância com o plano plurianual.
} 
Como assinalam Oliveira e Senna (2015), diante da situação histórica de globalização econômica e a necessidade urgente de inclusão social e redução das desigualdades, o PPA 20082011 define como agenda prioritária: o Programa de Aceleração do Crescimento (PAC), o Plano de Desenvolvimento da Educação (PDE) e a Agenda Social. Desse modo, o governo destaca o papel da educação e anuncia o PDE como elemento essencial dessa agenda, cuja meta é a qualidade da educação básica. A mensagem presidencial esclarece que

Com o PDE, pretendemos construir o início de um novo tempo, capaz de assegurar a primazia do talento, sobre a origem social, e a prevalência do mérito, sobre a riqueza familiar. A busca pela melhoria da qualidade da educação representa a conjugação dos esforços das Unidades da Federação atuando em regime de colaboração com as famílias e a comunidade (BRASIL, 2007a).

Como se vê, segundo o documento, o PDE visa fortalecer o regime de colaboração, recomendado no Art. 211 da Constituição Federal de 1988, ou seja, “a União, os Estados, o Distrito Federal e os Municípios organizarão, em regime de colaboração, seus sistemas de ensino" (BRASIL, 1988).

Diante disso, o mencionado decreto define 28 diretrizes que devem ser cumpridas pelos entes federados e acordadas em um Termo de Cooperação Técnica (BRASIL, 2007b). O Ministério da Educação (MEC) afirma no documento denominado "O Plano de Desenvolvimento da Educação: razões, princípios e programas", que esse Plano "agrega ingredientes novos ao regime de colaboração, de forma a garantir a sustentabilidade das ações que o compõem”. Para tanto, enfatiza que no lugar de "convênios unidimensionais e efêmeros, entram os Planos de Ações Articuladas (PAR), de caráter plurianual, que devem ser construídos com a participação de gestores e educadores locais" (BRASIL, 2007c, p. 24).

De acordo com o documento do MEC, o PAR “é multidimensional e sua temporalidade o protege daquilo que tem sido o maior impeditivo do regime de colaboração: a descontinuidade das ações, a destruição da memória do que foi adotado, a reinvenção, a cada troca de equipe do que já foi inventado". Em outras palavras, a intermitência. O documento acrescenta que "só assim se torna possível estabelecer metas de qualidade de longo prazo para que cada escola ou rede de ensino tome a si como parâmetro e encontre apoio para seu desenvolvimento institucional" (BRASIL, 2007c, p. 25).

Com isso, a União estabeleceu a política de regulação centralizada das transferências voluntárias e da assistência técnica do MEC aos estados e municípios. Assim, a adesão ao 
OLIVEIRA, Regina Tereza Cestari de; HAIDUCK, Carmen Lígia Caldas. Conselhos de Educação no âmbito do Plano de Ações Articuladas (PAR) em municípios de Mato Grosso do Sul.

compromisso e ao cumprimento de suas diretrizes por parte dos governos subnacionais exige a elaboração do PAR para recebimento de assistência técnica e financeira do MEC.

Em outras palavras,

O Plano de Ações Articuladas (PAR) é uma ferramenta de planejamento, de operacionalização e de avaliação das políticas educacionais, criada dentro dos moldes de um Estado federativo. O planejamento educacional é centralizado pelo Ministério da Educação, que, oferecendo apoio técnico e financeiro, induz os entes federados a assumirem responsabilidades na gestão da educação (FERREIRA; FONSECA, 2013, p. 281).

O PAR constitui, portanto, o arcabouço jurídico do PDE, na medida em que o Ministério da Educação se propõe a estabelecer um diálogo com os demais entes federativos. Assim, se apresenta como um instrumento para organizar as ações da escola e para melhorar a qualidade da educação, aferida, no entanto, pelo Índice de Desenvolvimento da Educação Básica (IDEB) (FONSECA, 2013).

Não é demais lembrar que esse Índice, criado em 2007, é calculado e divulgado periodicamente pelo Instituto Nacional de Estudos e Pesquisas Educacionais Anísio Teixeira (INEP), com base nos dados sobre rendimento escolar, combinados com o desempenho dos alunos, constantes do censo escolar e do Sistema de Avaliação Básica (SAEB), composto pela Avaliação Nacional da Educação Básica (ANEB) e a Avaliação Nacional do Rendimento Escolar (Prova Brasil) (BRASIL, 2007b).

Ressalte-se que o conceito de qualidade da educação reduzido a esse índice, contrapõe-se à concepção de qualidade social da educação, ou seja,

[...] caracterizada por um conjunto de fatores intra e extra-escolares que se referem às condições de vida dos alunos e de suas famílias, ao seu contexto social, cultural e econômico e à própria escola - professores, diretores, projeto pedagógico, recursos, instalações, estrutura organizacional, ambiente escolar e relações intersubjetivas no cotidiano escolar (DOURADO, 2007, p. 940-941).

A partir desse período, o planejamento dos sistemas/redes de educação passou a ser realizado, portanto, conforme as orientações do PAR, expressas no "Instrumento de Campo" (BRASIL, 2008). O Plano baseado em diagnóstico deverá identificar as medidas mais apropriadas para a gestão dos sistemas de ensino, com vista à melhoria da qualidade da educação básica (BRASIL, 2007b), estruturado em quatro dimensões: gestão educacional; formação de 
OLIVEIRA, Regina Tereza Cestari de; HAIDUCK, Carmen Lígia Caldas. Conselhos de Educação no âmbito do Plano de Ações Articuladas (PAR) em municípios de Mato Grosso do Sul.

professores e dos profissionais de serviço e apoio escolar; práticas pedagógicas e avaliação; infraestrutura física e recursos pedagógicos (BRASIL, 2007c).

Segundo o "Instrumento de Campo", cada dimensão é formada por áreas de atuação e cada área apresenta indicadores específicos, correspondentes a quatro critérios de pontuação, assim constituídos: pontuação 1 - indica uma situação crítica. Nesse caso, deve-se implementar um conjunto de ações imediatas (que no PAR denominam-se 'subações') para melhorar os resultados do indicador; pontuação 2 - indica uma situação insuficiente, com mais aspectos negativos do que positivos, sendo necessárias ações imediatas e estas poderão contar com o apoio técnico e/ou financeiro do MEC; pontuação 3 - indica uma situação satisfatória que apresenta mais aspectos positivos do que negativos, significando que estão sendo desenvolvidas, parcialmente, ações que favorecem o bom desempenho no indicador em questão; e pontuação 4 - indica uma situação positiva, sendo que para aquele indicador não serão necessárias ações imediatas (BRASIL, 2008).

No governo seguinte, o Plano Plurianual (PPA) 2012-2015, denominado "Plano Mais Brasil”, afirma em sua apresentação que,

O recente ciclo de desenvolvimento brasileiro vem sendo impulsionado por políticas públicas inovadoras que combinam crescimento econômico com redução das desigualdades sociais e regionais. Essas políticas têm um elemento comum: a recuperação da capacidade do Estado de planejar e agir visando, sobretudo, garantir os direitos dos que mais precisam (BRASIL, 2011b, p. 11).

Nesse sentido, assinala que a perspectiva contida nesse Plano:

[...] sinaliza para o papel da educação no aprofundamento da redução de desigualdades sociais e regionais no Brasil, sendo fator de promoção da inclusão numa sociedade que valoriza crescentemente o conhecimento como dimensão da cidadania, da igualdade social e do desenvolvimento econômico sustentável (BRASIL, 2011b, p. 83-84).

Nessa conjuntura, no Governo de Dilma Vana Rousseff (2011-2014), o PAR teve continuidade como instrumento de articulação entre os entes federados, abalizado pelas “Orientações gerais para elaboração do Plano de Ações Articuladas” (BRASIL, 2011a, p. 1).

No segundo ciclo do PAR (2011-2014), portanto, na Dimensão gestão educacional, os Indicadores da Área "Gestão Democrática: articulação e desenvolvimento do Sistema de Ensino" foram reorganizado. Entre eles, o Indicador 2, que no primeiro ciclo do PAR (2007-2010) compreendia "Existência, composição e atuação, do Conselho Municipal de Educação" 
(BRASIL, 2008, p. 18), e no segundo ciclo (2011-2014) alterou-se para "Existência, composição, competência e atuação do Conselho Municipal de Educação" (BRASIL, 2011b, p. 27), ou seja, acrescentou sua competência para avaliação pelos municípios.

Vale reforçar o caráter participativo que o PAR anuncia e que, segundo Ferreira e Fonseca (2011, p. 85), pode “[...] resguardar a organicidade das ações e outorgar autonomia ao ente municipal". Assim, é possível inferir a autonomia dos municípios no sentido de considerar os indicadores propostos nesse instrumento de planejamento, como é o caso da criação do Conselho Municipal de Educação por parte de alguns municípios de Mato Grosso do Sul.

\section{O Conselho Municipal de Educação no Plano de Ações Articuladas (PAR) em municípios sul-mato-grossenses}

É importante recordar, incialmente, que os Conselhos Municipais de Educação passaram a se institucionalizar no Brasil após a promulgação da Constituição Federal de 1988, que define os municípios como entes federados, autônomos (BRASIL, 1988) e, portanto, com a incumbência de estabelecer os seus Sistemas e Conselhos de Educação. Assim, "no processo de redemocratização da sociedade, os Conselhos Municipais de Educação inseridos na estrutura dos sistemas municipais de ensino passaram a representar uma das estratégias para democratizar as ações do Estado" (SANTOS, 2014, p. 61).

Esses Conselhos cresceram após a aprovação da Lei de Diretrizes e Bases da Educação Nacional (LDBEN), Lei n. 9.394, de 1996 e, principalmente, depois da aprovação da Lei do Fundo de Manutenção e Desenvolvimento do Ensino Fundamental e de Valorização do Magistério (FUNDEF), em 1997, “dada a consciência mais ampla de que eles já eram sistemas de ensino desde a Constituição de 1988" (CURY, 2000, p. 53).

Pode-se assinalar, utilizando as palavras de Cury (2000, p. 45), que a existência desses Conselhos, levando-se em conta o espírito das leis existentes,

[...] não é o de serem órgãos burocráticos, cartoriais e engessadores da dinamicidade dos profissionais e administradores da educação ou a autonomia dos sistemas. Sua linha de frente é, dentro da relação Estado e Sociedade, estar a serviço das finalidades maiores da educação e cooperar com o zelo pela aprendizagem nas escolas brasileiras.

Apesar de sua importância, enquanto órgão de Estado, o processo de criação foi lento em algumas regiões do país. Segundo dados do Instituto Brasileiro de Geografia e Estatística (IBGE), 
OLIVEIRA, Regina Tereza Cestari de; HAIDUCK, Carmen Lígia Caldas. Conselhos de Educação no âmbito do Plano de Ações Articuladas (PAR) em municípios de Mato Grosso do Sul.

no período de 2009 a 2014, o crescimento de Conselhos de Educação foi de 79,1\% em 2009, de 84,8\% em 2011 e de 87,5\% em 2014, nos municípios brasileiros (BRASIL, 2015). Ressalta-se que esse período corresponde à implementação do primeiro e segundo ciclos do PAR nesses municípios.

Os dados da "Pesquisa de Informações Básicas Estaduais e Municipais" apresentados no gráfico a seguir (BRASIL, 2015), indicam o número de Conselhos Municipais de Educação criados nos estados brasileiros até o ano de 2014.

Gráfico 1 - Percentual de Municípios com Conselho Municipal de Educação e com Conselhos Paritário por Unidade da Federação - 2014

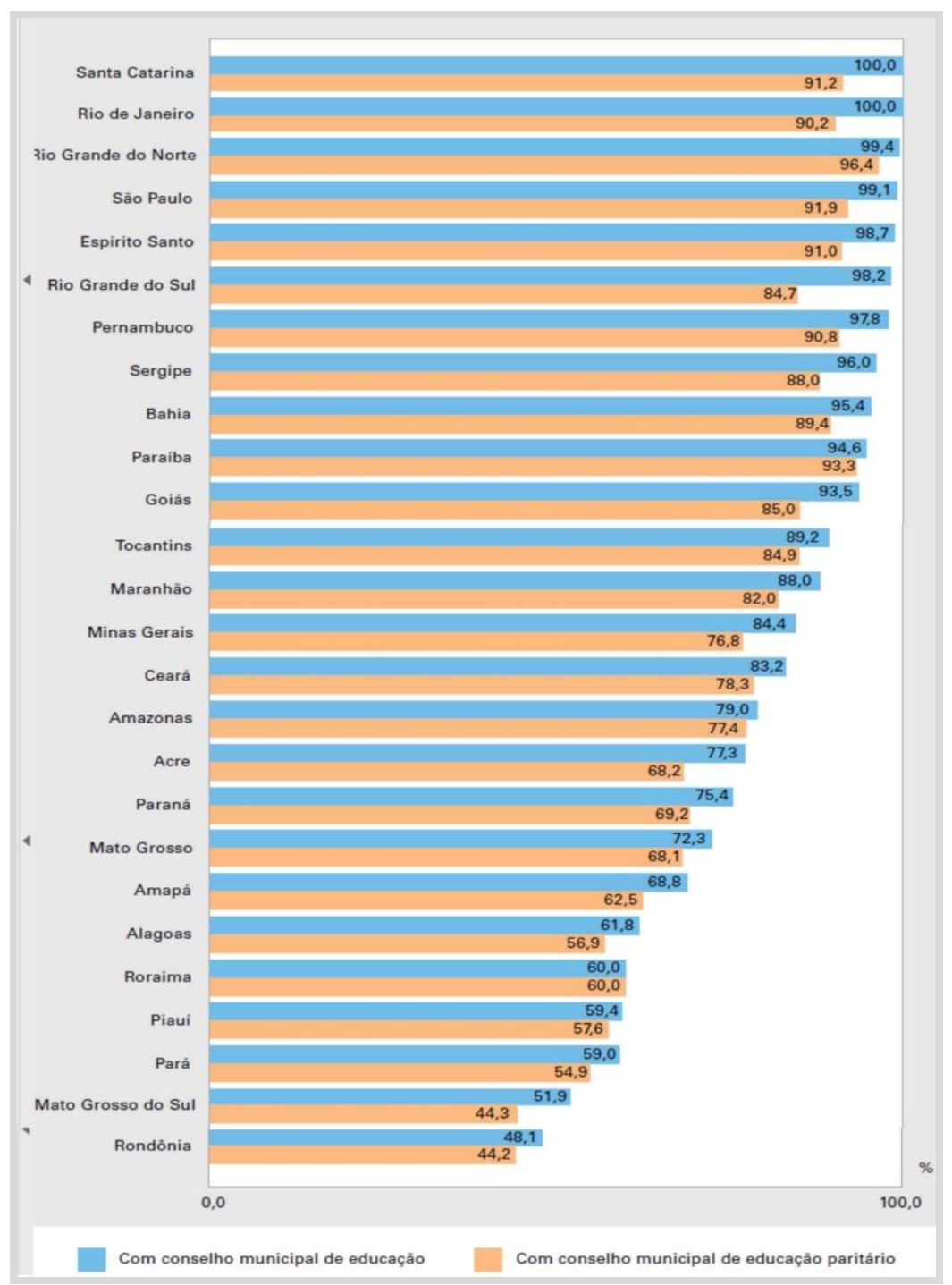

Fonte: BRASIL. Ministério do Planejamento, Orçamento e Gestão. Instituto Brasileiro de Geografia e Estatística - IBGE. Diretoria de Pesquisa. Perfil dos estados e municípios brasileiros: 2014. Coordenação de população e Indicadores Sociais. Rio de Janeiro: IBGE, 2015. p. 39. 
Observa-se, também, no gráfico, o percentual dos Conselhos Municipais de Educação nos estados brasileiros que apresentam paridade na sua composição. A paridade constitui uma das formas do perfil democrático desses Conselhos e a garantia de uma representação plural com integrantes da sociedade civil e da sociedade política (aparelho governamental).

Nota-se que o Estado de Mato Grosso do Sul figura entre os três estados da federação com o menor número de Conselhos Municipais de Educação, assim como de Conselhos paritários, ao lado dos estados de Rondônia e do Pará, conforme o percentual apresentado. Entre os 79 municípios que compõem o estado, 38 criaram esses Conselhos, que começaram a ser instituídos após a aprovação da Lei de Diretrizes e Bases da Educação Nacional (LDBEN), em 1996.

Os primeiros municípios a criar os seus Conselhos foram: Aparecida do Taboado (1997), Corumbá (1997), Dourados (1997) e Porto Murtinho (1997). No ano de 1998 foram criados os Conselhos Municipais de Campo Grande (capital do estado de Mato Grosso do Sul) e de Chapadão do Sul (MATO GROSSO DO SUL, 2016).

Ainda na década de 1990 foram criados os Conselhos de Educação nos seguintes municípios: Bataguassu (1999), Bela Vista (1999), Naviraí (1999). Nos anos de 2001 e de 2002, os municípios que criaram seus Conselhos foram: Antônio João (2001); Cassilândia (2002); Coronel Sapucaia (2002); Laguna Carapã (2002) e Paranhos (2002). E, no período de 2003 a 2006, nos seguintes municípios: Aral Moreira (2003); Miranda (2003); Amambai (2004); Sete Quedas (2005); Sonora (2005); Tacuru (2005); Aquidauana (2006); Nova Andradina (2006); Ribas do Rio Pardo (2006) e Selvíria (2006) (MATO GROSSO DO SUL, 2016).

Em 2007, ano de implantação do PAR, foram criados dois Conselhos, um no município de Caarapó, em setembro de 2007 e o outro no município de Ponta Porã, em novembro de 2007. No entanto, não é possível afirmar que sejam em decorrência desse planejamento.

Apresenta-se na Tabela 1, a seguir, a relação dos municípios localizados no estado de Mato Grosso do Sul, com Conselhos de Educação criados ao longo do primeiro ciclo e do segundo ciclo do PAR, a pontuação atribuída por cada município ao Indicador 2 "Existência, composição e atuação, do Conselho Municipal de Educação” (BRASIL, 2008, p. 18), no primeiro ciclo, os respectivos anos de criação desses Conselhos, assim como a população desses municípios, conforme o censo do IBGE (BRASIL, 2010) e a estimativa populacional do IBGE (BRASIL, 2014). 
OLIVEIRA, Regina Tereza Cestari de; HAIDUCK, Carmen Lígia Caldas. Conselhos de Educação no âmbito do Plano de Ações Articuladas (PAR) em municípios de Mato Grosso do Sul.

Tabela 1- Conselhos Municipais de Educação criados no primeiro ciclo do PAR 2007-2010 e no segundo ciclo do PAR 2011-2014

\begin{tabular}{|c|c|c|c|c|}
\hline Municípios & $\begin{array}{l}\text { População } \\
\text { Censo 2010 }\end{array}$ & $\begin{array}{c}\text { Estimativa } \\
\text { populacional } \\
2014\end{array}$ & $\begin{array}{l}\text { Pontuação } 1^{0} \\
\text { Ciclo do PAR }\end{array}$ & $\begin{array}{l}\text { Ano de } \\
\text { criação }\end{array}$ \\
\hline Água Clara & 14.424 & 14.474 & 2 & 2008 \\
\hline Anastácio & 23.835 & 24.748 & 1 & 2012 \\
\hline Brasilândia & 11.826 & 11.923 & 1 & 2014 \\
\hline Camapuã & 13.625 & 13.731 & 1 & 2009 \\
\hline Corguinho & 5.513 & 5.513 & NSA & 2013 \\
\hline Jardim & 24.346 & 25.473 & 1 & 2011 \\
\hline Ladário & 19.627 & 21.860 & 1 & 2012 \\
\hline Paranaíba & 40.192 & 41.495 & 1 & 2012 \\
\hline Rio Negro & 5.036 & 4.910 & NSA & 2011 \\
\hline $\begin{array}{l}\text { São Gabriel do } \\
\text { Oeste }\end{array}$ & 22.203 & 24.982 & 1 & 2011 \\
\hline Sidrolândia & 42.132 & 51.355 & NSA & 2012 \\
\hline Três Lagoas & 101.791 & 113.619 & 1 & 2010 \\
\hline
\end{tabular}

Fontes: BRASIL. Ministério do Planejamento, Orçamento e Gestão. Instituto Brasileiro de Geografia e Estatística - IBGE. Diretoria de Pesquisa. Perfil dos estados e municípios brasileiros: 2014. Coordenação de população e Indicadores Sociais. Rio de Janeiro: IBGE, 2015.

MATO GROSSO DO SUL. Conselho Estadual de Educação. Quadro demonstrativo dos Conselhos Municipais de Educação. 2016. Disponível em: <http://www.cee.ms.gov.br>. Acesso em: 10 ago. 2017.

Conforme os critérios de pontuação definidos para o Indicador 2, segundo as orientações do MEC, a pontuação 1 corresponde à ausência do Conselho Municipal de Educação (CME) implementado ou quando o CME existente é apenas formal (BRASIL, 2008). Essa pontuação foi atribuída pelos municípios de Anastácio, Brasilândia, Camapuã, Jardim, Ladário, Paranaíba, São Gabriel do Oeste e Três Lagoas, o que indica uma situação crítica e, portanto, a necessidade de ações imediatas, no caso, implantar o Conselho Municipal de Educação. 
A pontuação 2 indica uma situação insuficiente ao Indicador e considera para avaliação quando não existe um CME implementado, quer dizer, não tem regimento interno, a escolha dos conselheiros é feita por indicação e os diversos segmentos não estão representados. Além disso, especifica que zela em parte pelo cumprimento das normas, não auxilia no planejamento municipal de educação, na distribuição de recursos, no acompanhamento e avaliação das ações educacionais, em resumo, apenas valida o plano da Secretaria Municipal de Educação (BRASIL, 2008).

Verifica-se que somente o município de Água Clara conferiu a pontuação 2, enquanto os municípios de Corguinho, Rio Negro e Sidrolândia, que indicaram NSA ao Indicador, conforme as orientações, informaram a impossibilidade de pontuar esse Indicador. No entanto, criaram esses Conselhos no período correspondente ao segundo ciclo do PAR 2011- 2014.

Em síntese, desses municípios, três criaram o Conselho Municipal no primeiro ciclo do PAR 2007-2010 (Água Clara, Camapuã e Três Lagoas) e nove municípios (Anastácio, Brasilândia, Corguinho, Jardim, Ladário, Paranaíba, Rio Negro, São Gabriel do Oeste e Sidrolândia) no segundo ciclo do PAR 2011-2014.

Diante do exposto, é possível considerar o impulso da política educacional do período para o crescimento dos Conselhos Municipais de Educação no país, especialmente em Mato Grosso do Sul, destacando-se a centralidade do PAR como indutor desse crescimento. É importante mencionar que se trata de um Indicador importante, entendendo-se que nos Conselhos “[...] torna-se possível a (re)entrada da sociedade civil no âmbito dos governos a fim de fiscalizálos e mesmo controlá-los". A eles compete "trilhar a via de mão dupla que vai do Estado à Sociedade e desta para aquele" (CURY, 2000, p. 51 e 60).

Como assinala o autor, a origem etimológica da expressão Conselho,

[...] vem do latim Consilium. Por sua vez, consilium provém do verbo consulo/consulere, significando tanto ouvir alguém quanto submeter algo a uma deliberação de alguém, após uma ponderação refletida e de bom senso. Trata-se, pois, de um verbo cujos significados postulam a via de mão dupla: ouvir e ser ouvido (CURY, 2000, p. 47, grifos do autor).

Esses significados postulam, portanto, ação coletiva, plural, interesses comuns, embora não homogêneos, por parte do grupo que o compõe. Nesse sentido, o Conselho Municipal de Educação, entendido como órgão colegiado de interlocução entre Estado e Sociedade, dependendo da pluralidade representativa, poderá contribuir com o processo de gestão 
democrática em âmbito local, ou se perder na tecnocracia, quando ocupado "[...] por pessoas alheias aos e despreparadas para os assuntos específicos, eles poderão se desviar do essencial, seja no conteúdo, seja na forma”, como afirma Cury (2000, p. 49).

Embora a colegialidade não seja garantia de gestão democrática, entende-se que é a modalidade mais próxima de concepções democráticas de caráter participativo, um elemento teoricamente superior à liderança unipessoal, monocrática não letiva, eventualmente autocrática, como assevera Lima (2013). O autor acentua a importância da participação na tomada de decisões como elemento insubstituível no exercício da gestão democrática. Em suas palavras,

O poder de decidir, participando democraticamente e com os outros nos respectivos processos de tomada das decisões representa o âmago da democracia e, consequentemente, sem participação na decisão não é possível conceber uma gestão democrática das escolas na perspectiva do seu autogoverno (LIMA, 2014, p. 1072).

Importa, assim, reforçar que a participação, no sentido de tomada de decisão e deliberação pública, confere sentido à gestão democrática da educação, associada a outros elementos como autonomia e pluralidade representativa. Nesse sentido, a atuação do Conselho Municipal de Educação “[...] pode significar controle social e político das ações do Estado pela sociedade civil, em decorrência de sua composição plural” (WERLE; THUM; ANDRADE, 2008, p. 88).

\section{Considerações finais}

A reflexão que se pode fazer a partir das considerações apresentadas no texto é que o PAR ganhou centralidade na condução das políticas educacionais, no contexto do Plano de Desenvolvimento da Educação (PDE), ao longo do segundo mandato do governo de Lula da Silva (2007-2010), tendo continuidade no governo de Dilma Vana Rousseff (2011-2014).

É importante frisar que, conforme Dourado (2007, p. 928), apesar de o PDE apresentar, por um lado, “[...] indicações de grandes e importantes ações direcionadas à educação nacional”, por outro, "[...] não está balizado por fundamentação técnico-pedagógica suficiente e carece de articulação efetiva entre os diferentes programas e ações em desenvolvimento pelo próprio MEC e as políticas propostas".

Em que pese essa constatação, o governo federal, nesse período, pautou sua atuação pelo princípio da defesa da educação de qualidade, embora focalizada no IDEB, a partir do binômio inclusão e democratização. Nesse cenário contraditório das ações governamentais, destacam-se 
algumas dessas ações como a ampliação do ensino fundamental de oito para nove anos, as políticas de ação afirmativa e, de modo estrutural, a criação do Fundo de Manutenção e Desenvolvimento da Educação Básica e de Valorização dos Profissionais da Educação (FUNDEB) (DOURADO, 2007).

Nesse mesmo cenário, o PAR, instrumento de articulação entre os entes federados, traduziu a leitura do poder executivo no que se refere a sua obrigação prevista no art. $211, \S 1^{\circ}$ da Constituição Federal $^{3}$, como analisa Sena (2013).

Diante do exposto, pode-se afirmar que o PAR instituiu a cultura do planejamento e a ruptura da tradição política de projetos de balcão, por meio de apoio técnico e financeiro da União aos municípios. Porém, a coordenação federativa “[...] implicou algum grau de centralização e diminuição do espaço de autonomia dos Estados e municípios, considerados como executores de políticas e não como formuladores" (SENA, 2013, p. 140), na medida em que não contou, na sua elaboração, com a participação efetiva de setores históricos organizados da sociedade civil brasileira, principalmente no campo educacional.

No entanto, possibilitou aos municípios, principalmente por meio do diagnóstico, visualizar as características da educação na esfera local e destacou a gestão educacional e seus instrumentos de articulação e de controle social, como os Conselhos de Acompanhamento do FUNDEB, os Conselhos de Alimentação Escolar, assim como a presença de conselhos de educação, os Conselhos Escolares e, especialmente, os Conselhos Municipais de Educação, considerando-os indicadores de gestão democrática.

Os dados mostraram o crescimento dos Conselhos de Educação nos municípios brasileiros, entre eles, nos municípios localizados em Mato Grosso do Sul, podendo-se inferir que esse crescimento se deu em decorrência da política indutiva do PAR, coordenada pelo MEC.

Entende-se que esses Conselhos, com funções deliberativas, normativas e consultivas, embora com contradições intrínsecas, são importantes espaços públicos de mediação entre Estado e sociedade, com potencial para formular, acompanhar e avaliar as políticas educacionais, no âmbito de sua esfera de atuação.

\footnotetext{
${ }^{3}$ De acordo com o art. 211, § $1^{\circ}$ da Constituição Federal de 1988 (BRASIL, 1988): “A União organizará o sistema federal de ensino e o dos Territórios, financiará as instituições de ensino públicas federais e exercerá, em matéria educacional, função redistributiva e supletiva, de forma a garantir equalização de oportunidades educacionais e padrão mínimo de qualidade do ensino mediante assistência técnica e financeira aos Estados, ao Distrito Federal e aos Municípios".
} 
OLIVEIRA, Regina Tereza Cestari de; HAIDUCK, Carmen Lígia Caldas. Conselhos de Educação no âmbito do Plano de Ações Articuladas (PAR) em municípios de Mato Grosso do Sul.

\section{Referências}

BRASIL. Constituição da República Federativa do Brasil. Diário Oficial da União, Brasília 5 out. 1988. Disponível em: <www.planalto.gov.br/ccivil>. Acesso em: 20 abr. 2012.

BRASIL. Decreto ${ }^{\circ}$ 6.094, de 24 de abril de 2007. Dispõe sobre a implementação do Plano de metas Compromisso Todos pela Educação, pela União Federal, em regime de colaboração com Municípios, Distrito Federal e Estados, e a participação das famílias e da comunidade, mediante programas e ações de assistência técnica e financeira, visando a mobilização social pela melhoria da qualidade da educação básica. Brasília, 2007b. Disponível em <www.planalto.gov.br/ccivil_03>. Acesso em: 25 fev. 2012.

BRASIL. Instituto Brasileiro de Geografia e Estatística - IBGE. Cidades. Rio de Janeiro: IBGE, 2014. Disponível em: <https://cidades.ibge.gov.br/xtras/fontes.php>. Acesso em: 15 nov. 2015.

BRASIL. Ministério da Educação. Instrumento de Campo. Brasília: MEC, 2008. Disponível em: <http://portal.mec.gov.br/arquivos/pdf/diagnostico.pdf>. Acesso em: 13 set. 2010.

BRASIL. Ministério da Educação. Orientações Gerais para elaboração do Plano de Ações Articuladas. Brasília: MEC, mar. 2011a.

BRASIL. Ministério da Educação. O Plano de Desenvolvimento da Educação: razões, princípios e programas. Brasília: MEC, 2007c.

BRASIL. Ministério do Planejamento, Orçamento e Gestão. Instituto Brasileiro de Geografia e Estatística - IBGE. Censo Demográfico 2010. Brasília: MP, 2010. Disponível em:< https://censo2010.ibge.gov.br/ sinopse/index.php?dados=8>. Acesso em: 13 ago. 2016.

BRASIL. Ministério do Planejamento, Orçamento e Gestão. Secretaria de Planejamento e Investimentos Estratégicos. Plano plurianual 2008-2011: projeto de lei / Ministério do Planejamento, Orçamento e Gestão, Secretaria de Planejamento e Investimentos Estratégicos. Brasília: MP, 2007a. Disponível em <http://www.planejamento.gov.br/secretarias/upload/arquivo/spi-1/ppa1/2008/081015_ppa_2008_ mespres.pdf>. Acesso em: 20 abr. 2012

BRASIL. Ministério do Planejamento, Orçamento e Gestão. Secretaria de Planejamento e Investimentos Estratégicos. Plano plurianual 2012-2015. Brasília: MP, 2011b. Disponível em: <http://www.ufrgs.br/elaboracaopdi2016/links-e-arquivos/PPA_Principal.pdf>. Acesso em: 20 set. 2017.

BRASIL. Ministério do Planejamento, Orçamento e Gestão. Instituto Brasileiro de Geografia e Estatística - IBGE. Diretoria de Pesquisa. Perfil dos estados e municípios brasileiros: 2014. Coordenação de população e Indicadores Sociais. Rio de Janeiro: IBGE, 2015.

CURY, Carlos Roberto Jamil. Os conselhos de educação e a gestão dos sistemas. In: AGUIAR, Márcia Ângela da S.; FERREIRA, Naura Syria Carapeto. (Org.). Gestão da educação: impasses, perspectivas e compromissos. 5. ed. São Paulo: Cortez, 2000. p. 43-60.

DOURADO, Luiz Fernandes. Políticas e gestão da educação básica no Brasil: limites e perspectivas. Educação e Sociedade, Campinas, v. 28, n. 100, especial, p. 921-946, out. 2007.

FERREIRA, Eliza Bartolozzi; FONSECA, Marília. O planejamento das políticas educativas no Brasil e seus desafios atuais. Perspectiva, Florianópolis, v. 29, n. 1, p. 69-96, jan./jun. 2011.

FERREIRA, Eliza Bartolozzi; FONSECA, Marília. Plano de ações articuladas (PAR): discutindo dados da pesquisa em rede. In: FERREIRA, Eliza Bartolozzi; FONSECA, Marília. Política e planejamento educacional no Brasil do século 21. Brasília: Liber Livro, 2013. p. 281-298. 
OLIVEIRA, Regina Tereza Cestari de; HAIDUCK, Carmen Lígia Caldas. Conselhos de Educação no âmbito do Plano de Ações Articuladas (PAR) em municípios de Mato Grosso do Sul.

FONSECA, Marília. Planejamento educacional no Brasil: um campo de disputas entre as políticas de governo e as demandas da sociedade. In: POLÍTICA e planejamento no Brasil do Século 21. Brasília: Liber Livro, 2013. p. 83-103.

LIMA, Licínio C. Diretor (a) de escola pública: unipessoalidade e concentração do poder no quadro de uma relação subordinada. In: PERONI, Vera Maria Vidal. (Org.). Redefinições das fronteiras entre o público e o privado: implicações para a democratização da educação. Brasília: Liber Livro, 2013. p. 5881.

LIMA, Licínio C. Gestão democrática das escolas: do autogoverno à ascensão de uma pós-democracia gestionária? Educação e Sociedade, Campinas, v. 35, n. 129, p. 1067-1083, 2014.

MATO GROSSO DO SUL. Conselho Estadual de Educação. Quadro demonstrativo dos Conselhos Municipais de Educação. 2016. Disponível em: <http://www.cee.ms.gov.br〉. Acesso em: 10 ago. 2017.

OLIVEIRA, Regina Tereza Cestari; SENNA, Ester. Educação básica no primeiro decênio do século XXI: entre a política de inclusão e a efetivação de direitos sociais. In: BACKES, José Licínio; OLIVEIRA, Regina Tereza Cestari; PAVAN, Ruth. (Org.). Políticas educacionais, currículo e diversidade cultural na educação básica. Campinas: Mercado de Letras, 2015. p. 103 -126.

SANTOS, Paulo Eduardo dos. Institucionalização dos Conselhos Municipais de Educação nas capitais brasileiras: a luta por uma nova hegemonia política. 2014. Tese (Doutorado em Educação) - Programa de Pós-Graduação em Educação, Universidade Federal de Goiás, Goiânia, 2014.

SAVIANI, Dermeval. PDE - Plano de desenvolvimento da educação: análise crítica da política do MEC. Campinas: Autores Associados, 2009.

SENA, Paulo. Planejamento educacional e federalismo no Brasil. In: FERREIRA, Eliza Bartolozzi; FONSECA, Marília. (Org.). Política e planejamento educacional no Brasil do século 21. Brasília: Liber Livro, 2013. p. 123-157.

WERLE, Flavia Obino Corrêa; THUM, Adriane Brill; ANDRADE, Alenis Cleusa. O sistema municipal de ensino e suas implicações para a atuação do conselho municipal de educação. Revista Brasileira de Política e Administração da Educação, Porto Alegre, v. 24, n. 1, p. 79 -109, jan./abr. 2008.

\author{
Regina Tereza Cestari de Oliveira \\ Universidade Católica Dom Bosco - UCDB | Programa de Pós- \\ Graduação em Educação \\ Campo Grande | MS | Brasil. Contato: reginacestari@ hotmail.com \\ ORCID 0000-0001-5500-7478 \\ Carmen Lígia Caldas Haiduck \\ Universidade Católica Dom Bosco - UCDB | Programa de Pós- \\ Graduação em Educação \\ Campo Grande | MS | Brasil. Contato: c-ligia@uol.com.br \\ ORCID 0000-0001-6568-2354
}

Artigo recebido em: 3 jan. 2018 e aprovado em: 15 mar. 2018. 